\title{
The Role of Macrophage Migration Inhibitory Factor in Critical Illness
}

\author{
Steffen Rex ${ }^{1,6, *, \#, \text { Sandra Kraemer }}{ }^{2,3, \#}$, Gerrit Grieb ${ }^{2,4}$, Christoph Emontzpohl ${ }^{2}$, Josefin Soppert ${ }^{2}$, \\ Andreas Goetzenich ${ }^{3}$, Rolf Rossaint ${ }^{5}$, Jürgen Bernhagen ${ }^{2, * \#}$ and Christian Stoppe ${ }^{2,5, \#}$
}

\begin{abstract}
${ }^{I}$ Department of Anesthesiology, University Hospitals Leuven, KU Leuven, Belgium; ${ }^{2}$ Institute of Biochemistry and Molecular Cell Biology, RWTH Aachen University, Germany; ${ }^{3}$ Department of Thoracic, Cardiac and Vascular Surgery, University Hospital, RWTH Aachen, Germany; ${ }^{4}$ Department of Plastic Surgery, Hand Surgery, Burn Unit, University Hospital, RWTH Aachen, Germany; ${ }^{5}$ Department of Anesthesiology, University Hospital of the RWTH Aachen, Germany; ${ }^{6}$ Department of Cardiovascular Sciences, KU Leuven, Belgium
\end{abstract}

\begin{abstract}
Emerging evidence suggests a pivotal role of macrophage migration inhibitory factor (MIF) in the systemic inflammatory immune response. MIF is located in preformed cytoplasmic vesicles of various cell types, which enables a rapid release after different stimuli like inflammation, surgical stress or ischemia and reperfusion. MIF is a known key player in the inflammatory response and contributes to several biological functions including the control of cell cycle (through activation of ERK1/2), sensing of pathogen stimuli (upregulation of TLR4 expression), recruitment of various immune cells (neutrophils, monocytes, $t$ cells) and prevention of p53-mediated apoptosis of macrophages. While MIF`s pro-inflammatory effects are crucial for an effective host defense, elevated MIF levels were repeatedly shown to be associated with the development of organ dysfunction and deleterious sequelae. Even more puzzling, increasing evidence indicates a protective role of this pleiotropic cytokine during ischemia and reperfusion injury in the myocardium. This review focuses on new insights regarding the biological significance of MIF release in the context of critical illness and ischemia/reperfusion.
\end{abstract}

Keywords: Chemokine, inflammation, macrophage migration inhibitory factor, multiple organ failure, sepsis, critical illness, systemic inflammatory response syndrome.

\section{INTRODUCTION}

The pleiotropic cytokine MIF is an evolutionary conserved protein that is known to act as a key player in the innate and adapted immune response. It is known to mediate several chronic and acute inflammatory diseases including rheumatoid arthritis, atherosclerosis, acute respiratory distress syndrome (ARDS) and sepsis [1].

Sepsis is one of the most common reasons for admission to the intensive care unit (ICU) and the number of cases is constantly increasing. It belongs to the leading causes of death in critically ill ICU patients [2, 3]. Despite growing knowledge about the pathophysiology of inflammation and sepsis, the treatment recommendations mainly focus on supportive strategies (e.g. fluid resuscitation and vasopressor therapy) and the early application of antibiotics. A number of auspicious pharmaco-therapeutic approaches were unable to demonstrate positive effects, such as the inhibition of tumornecrosis factor (TNF)- $\alpha$, the modulation of relative adrenal insufficiency

*Address correspondence to these authors at the Institute of Biochemistry and Molecular Cell Biology, University Hospital of the RWTH Aachen, Pauwelsstraße 30, 52074 Aachen, Germany; Tel: +49-241- 80 88833; Fax: +49-241-80 82427; E-mail: jbernhagen@ukaachen.de; and Department of Anesthesiology, University Hospitals Leuven, Herestraat 49, 3000 Leuven, Belgium; Tel: +32-1634-1374; Fax: +32-1634-4245;

E-mail: steffen.rex@gmail.com

"Authors contributed equally. and the administration of activated protein $\mathrm{C}$ in critical ill patients [4-6]. Previous experimental studies highlighted that inhibition of MIF resulted in a significantly reduced mortality from septic shock $[7,8]$, whereas clinical evidence is still lacking. In apparent contrast, emerging evidence indicates that MIF provides protective effects on the myocardium in the setting of ischemia-reperfusion and in distinct infectious diseases [9-12].

These intriguing findings demonstrate an ambiguous role for MIF under different clinical conditions that warrants further investigation in the context of distinct clinical settings.

\section{THE ROLE OF MIF IN THE IMMUNE SYSTEM}

The body`s first line defense mechanism is represented through the innate immune system that is directly activated by specified sentinel cells after recognition of any pathogenic stimulus [13]. The interaction between pathogen-associated molecular patterns (PAMPs) and their receptors (e.g. toll-like receptors (TLR)) stimulates numerous signal transduction pathways and transcription of several immune genes that further leads to the liberation of cytokines with immuneregulatory functions [1]. These cytokines are known to orchestrate the cellular and humoral immune reaction to inflammatory stimuli. While previous studies reported that animals with mutated/deleted genes of cytokines or their receptors demonstrated an increased susceptibility to complications from infections [1], the uncontrolled 
inflammatory response with overwhelming release of inflammatory mediators is known to contribute to the development of severe complications and worsen outcome of patients with sepsis and septic shock [14].

MIF belongs to the group of pro-inflammatory cytokines, which has been discovered by David and colleagues [15]. Since first experiments demonstrated MIF's inhibitory effects on $\mathrm{T}$ cell migration in vitro, the name "macrophage migration inhibitory factor" was defined. Nevertheless more than 50 years passed until new studies highlighted MIF's functions as a cytokine, being released from the pituitary gland after exposure to endotoxins (lipopolysaccharide) and reported on its regulatory function in response to infectious stimuli [16]. Further experimental studies followed that showed the beneficial effect of immune-neutralization of MIF on survival of mice with endotoxic shock. In addition, these findings demonstrated that MIF is capable to counteract the immunosuppressive effects of glucocorticoids $[16,17]$. These observations suggested that the severity of endotoxic shock is affected by the balance between circulating MIF levels (pro-inflammatory effects) and glucocorticoids (anti-inflammatory effects). By this, a previously unrecognized endogenous antagonist of glucocorticoids was identified. These findings early indicated a crucial role of MIF as potential cross-link between the endocrine and immune system. Given these findings, many studies were initiated to further characterize the role of MIF in the inflammatory response [1]. Importantly Leng and colleagues demonstrated that the pro-inflammatory effects of MIF may be mediated by signal transduction, triggered upon binding to the major histocompatibility complex, class-II invariant chain, CD74 [18].

\section{CHEMOKINES AND THEIR RECEPTORS}

Besides MIF's pivotal role in the innate and acquired immunity, it was demonstrated to promote the progression of atherosclerosis by activating pro-inflammatory atherogenic pathways and has repeatedly been demonstrated to function as potent chemokine-like cytokine [19, 20]. Chemokines belong to a group of small chemotactic cytokines, which are divided into 4 subgroups according to their N-terminal cystein motif $\left(\mathrm{C}, \mathrm{CC}, \mathrm{CXC}, \mathrm{CX}_{3} \mathrm{C}\right)$. Basically, chemokines are associated with inflammation owing to their leukocyte recruitment properties [21]. However, chemokines have a pivotal impact on other non-immune cells including endothelial, smooth muscle and epithelial cells. In particular, the effects of chemokines on endothelial cells result in stimulating (angiogenic) or inhibiting (angiostatic) effects [22]. The most important chemokines for angiogenesis are those of the CXC chemokine family exhibiting either angiogenic or angiostatic effects. That counteracting behaviour can be attributed to differences in structure and receptor binding [23]. The chemokines have different receptor binding characteristics resulting from their N-terminal sequence, the so called ELR motif (glutamic acid - leucine - arginine), consisting of three amino acids, [24]. Chemokines containing this ELR motif (ELR ${ }^{+}$chemokines) generally have positive effects on angiogenesis whereas those without the ELR motif (ELR ${ }^{-}$chemokines) exhibit anti-angiogenic properties.
Chemokines bind to a specific subclass of seventransmembrane-spanning $G$ protein-coupled receptors, termed chemokine receptors. Binding of chemokines to their receptor triggers either direct migration or chemotaxis. Today there are about 20 different chemokine receptors known, which are expressed on a variety of cell types, but predominantly on leukocytes [21]. The names of the receptors are inspired by their chemokine attractant. Various experimental approaches already examined the inhibition of receptorligand interaction, chemokine-glycosaminoglycan interaction, heteromerization, and the interference with the signaling pathways which are induced upon receptor activation [25].

\section{MIF RECEPTORS}

Leng et al. were the first to demonstrate a high affinity binding between MIF and the type II transmembrane protein CD74 [18]. This interaction was reported to be essential for a MIF-induced activation of the extracellular signal-regulated kinase-1/2 (ERK) mitogen-activated protein kinases (MAPK) cascade, leading to ERK1-MAPK phosphorylation and activation, as well as cell proliferation and prostaglandin (PG) $E_{2}$ production [18]. The fact that not all cells which are targeted by MIF express CD74 (e.g. neutrophils), led to the idea of additional, previously unrecognized members in the MIF receptor family, which are supposed to be involved in inflammatory diseases [16]. Recently, MIF was identified to be a non-cognate ligand of the chemokine receptors CXCR2 and CXCR4 [20]. CXCR2 and its cognate ligands CXCL8 and CXCL1 play an important role in the progression of atherosclerosis by recruiting neutrophils and monocytes into atherosclerotic lesions [26]. Deletion of CXCL1 in an atherogenic mouse model leads to less reduction of lesion size than the $C x c r 2$ knockout [27], suggesting that additional CXCR2 ligands are involved in the pro-atherogenic effects. One such relevant ligand was found to be MIF, which shares structural homology with the CXCL8 homodimer [28]. The high affinity interaction of MIF with CXCR2 triggers the directed migration of monocytes and neutrophils. Complex formation between CXCR2 and CD74 is suggested to amplify the GPCR's response [20].

Beside the revealed interaction of MIF with CXCR2 and CD74, CXCR4 has been identified as a second receptor within the chemokine receptor family. The identification of MIF as a non-cognate ligand of CXCR4 as well as the discovery of CXCR7 as additional receptor for CXCL12/ SDF- $1 \alpha$ disproved the assumption that the CXCL12/CXCR4 interaction is highly specific and non-promiscuous [29]. The main functions of the CXCL12/CXCR4 axis are stem cell homing and leukocyte recruitment to injured and inflamed tissue as well as the involvement in atherogenesis, tumorgenesis and metastasis [20, 30-32]. Accordingly, it could be demonstrated that blocking MIF affected the CXCR4-related $\mathrm{T}$ cell recruitment in a negative manner [16]. This might be of particular interest since $\mathrm{T}$ cell recruitment is critically involved in the formation of atherosclerotic lesions. Therefore CXCR4 was identified as key player in the progression of atherosclerosis [16]. Recently, also CXCR7 has been suggested to interact with MIF in a non-cognate manner [33]. Despite increasing evidence about the interaction between MIF and CXCR7, the significance of this binding remains speculative and has to be investigated in future. 
Since MIF was shown to control atherogenic leukocyte recruitment through high affinity interactions with the chemokine receptors CXCR2 and CXCR4, but cannot be formally grouped into the known chemokine families since it lacks the N-terminal cysteine motif, it is classified among the "chemokine-like function" (CLF) chemokines. This group also includes high mobility group binding protein-1 (HMGB1), Y-box protein-1 (YB-1) [34], $\beta$-defensins (HBDs) [35], autoantigenic aminoacyl tRNA synthetases (AaaRS) [36] or thioredoxin (TRX). CLF-chemokines are generally secreted by nonclassical export and/or following cell apoptosis and exhibit chemokine-like pro-migratory activities. For various CLF-chemokines like MIF, HBDs or some AaaRS classical chemokine receptors have been identified. For others (including HMGB1) complex formation with the CXCR4 ligand SDF- $1 \alpha$ was shown to influence SDF- $1 \alpha$ mediated signaling via its receptor.

\section{MIF IN THE INFLAMMATORY RESPONSE}

The production and release of TNF- $\alpha$, IL-1 $\beta$, IL-2, IL-6, IL-8, IL-12, IFN- $\gamma$ [1, 37-39], nitric oxide [1], matrix metalloproteinase [40] and prostaglandin $\mathrm{E}_{2}\left(\mathrm{PGE}_{2}\right)[41]$ is controlled by MIF, which was demonstrated through the genetic deletion of MIF that resulted in a significantly lower secretion of TNF- $\alpha$, IL- $1 \beta$ and $\mathrm{PGE}_{2}$ from macrophages [37, 42]. Therefore MIF was considered as a crucial upstream regulator of the innate immune reaction.

Furthermore MIF shows unique characteristics through its rapid release in response to any pathogenic stimulus from several cell types including dendritic cells, B and T cells and macrophages [20], which is due to its storage in preformed intracellular pools [1]. In particular the latter characteristic of MIF significantly differs from other pro-inflammatory cytokines that first need a transcriptional activation and translation of mRNA prior to secretion [43].

Besides MIF's characteristics as fast responding cytokine, it shows further important functional properties including the induction of TLR 4 expression, hereby facilitating the sensing of pathogens [41]. Moreover, it regulates the cell cycle, cell growth and apoptosis through stimulation of ERK1/2 [44] and the tumor suppressor protein p53 [1]. The pro-survival kinase ERK1/2 characterizes a distinct subfamily of the mammalian MAP kinases that are ubiquitously expressed. The control of cell cycling further depends on activation of additional signaling kinases and following stimulation of transcription factors and/or further downstream protein kinases, such as the c-Jun N-terminal kinases (JNK). MIF is known to regulate many important cell functions, including the differentiation, proliferation and apoptosis of different cells. In this context, Lue and colleagues recently demonstrated the CXCR4 mediated stimulation of JNK signaling pathway in $\mathrm{T}$ cells and fibroblasts. Furthermore they showed that this process was co-dependent on CD74 [45]. Based on these findings, the investigators supposed that MIF is even capable to promote the inflammatory response by inhibition of JNK-mediated apoptosis of immune cells $[11,45]$. Previous studies reported that increased MIF concentrations blocked the accumulation of p53 in macrophages and thus promoted a prolonged survival of monocytes and macrophages, which may lead to a more efficient eradication of pathogens through sustained proinflammatory action and constant production of IL-1 $\beta$, TNF$\alpha$ and $\mathrm{PGE}_{2}$ [40]. In contrast it is known that an unbalanced pro-inflammatory response is associated with harmful complications and may contribute to the development of shock $[37,40]$. Indeed, previous animal studies demonstrated that a genetic deletion or immuno-neutralization of MIF protected mice from the consequences of inflammatory shock $[15,40]$.

A summary of the versatile functions of MIF in the immune system is illustrated in (Figure 1).

\section{THE INTERACTION BETWEEN MIF AND THE COP9 SIGNALOSOME COMPLEX}

In extension to the previous mentioned pathways, MIF was recently identified to regulate cell cycling by controlling the c-Jun activation domain binding protein (JAB) 1/COP9 signalosome subunit (CSN) 5. The COP9 signalosome complex consists of eight core subunits, called CSN1 -

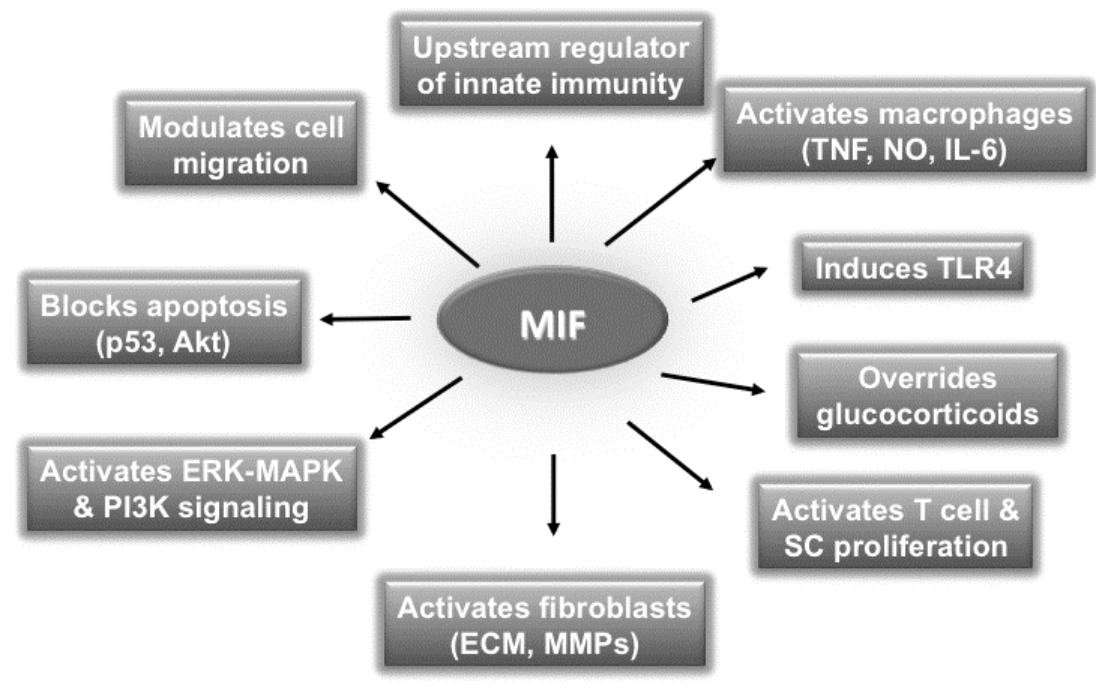

Fig. (1). MIF`s multiple functions in the immune system. 
CSN8. CSN is highly conserved across diverse species and is crucially involved in the development of mammalians. The cell cycle and checkpoint control is one of the many important topics in which CSN is involved. The complex mediates ubiquitin-proteasome dependent protein degradation via deneddylation/deubiquitination [46].

CSN5, (also called JAB1) is an intracellular binding protein of MIF and was demonstrated to inhibit the AP-1 transcription as well as JNK activity [47]. Furthermore CSN5 is capable to control the cell cycle via p27Kip1 as binding to CSN5 leads to cell cycle progression, export of p27Kip1 from the nucleus and its accompanied degradation. MIF has been shown to inhibit this mechanism through binding to CSN5 resulting in an increased amount of p27Kip1. Interestingly, it has been reported that MIF is capable to block the CSN5 mediated rescue of fibroblast growth arrest that results from serum starvation [47].

\section{THE ROLE OF MIF IN INFECTIOUS AND ACUTE INFLAMMATORY DISEASES}

MIF secretion in healthy persons follows a circadian rhythm with maximal MIF release in the morning. Circulating MIF values range between 2 to $10 \mathrm{ng} / \mathrm{ml}$ [48]. In contrast, circulating MIF levels significantly increased in septic patients, with median concentrations reaching up to $18 \mathrm{ng} / \mathrm{ml}$ $(6.6-154.4 \mathrm{ng} / \mathrm{ml})[1,7]$. Once pathogens are recognized, MIF is released by numerous cells (including $\mathrm{T}$ and $\mathrm{B}$ cells, dendritic cells, neutrophils, monocytes, macrophages, mast cells, basophils, or eosinophils). Alternatively, tissues that are in direct contact with the environment (e.g., lungs and the gastrointestinal tract) directly express MIF [49].

About 30 years ago, Bernhagen and colleagues were the first to indicate that MIF is primordially involved in the pathophysiological cascades of sepsis $[7,16]$. Accordingly, Calandra et al. demonstrated circulating MIF levels to overwhelmingly increase in septic patients [7]. Subsequently, Beishuizen et al. reported that survivors from septic shock had significantly lower MIF values when compared to nonsurvivors [50]. In septic shock, elevated MIF values were found to predict outcome-deterioration [37] and mortality [8]. In septic patients with disseminated intravascular coagulation (DIC), Gando et al. described a correlation between circulating MIF levels and soluble fibrin levels. It was therefore concluded that MIF could be implicated in activating pro-thrombotic pathways in septic patients suffering from DIC [51].

Considering the overwhelming release of reactive oxygen species in septic patients, it is important to note the antioxidant properties of MIF [12, 49, 52] being comparable to thioredoxin (Trx)-1. Due to its intrinsic thiolprotein oxidoreductase (TPOR) activity, MIF is capable of attenuating oxidative stress $[12,49]$. In septic patients, MIF was found to correlate with elevated plasma levels of Trx, hereby counteracting oxidative stress by restoring the redox homeostasis [53].

Furthermore, in patients with encephalitis and meningitis, significantly increased MIF levels have been measured in the cerebrospinal fluid. In patients with cerebral infections, Østergaard and Benfield reported elevated MIF levels and severity of illness to be correlated [54, 55]. In children, MIF gene polymorphisms were suggested to affect occurrence, severity and outcome of meningococcal disease [56].

For urinary tract infections, Otukesh and colleagues described the use of MIF levels for the localization of infections. In patients with acute cystitis, the MIF/creatinine ratio was significantly lower than in patients with pyelonephritis, possibly indicating infiltration of kidneys by immune cells [57].

Also in ARDS, MIF seems to have an important role. Within the bronchial epithelium, the pulmonary capillary endothelium, and the alveolar macrophages, there is a constitutive MIF expression. When compared to healthy controls, ARDS-patients have significantly higher MIF levels in bronchoalveolar (BAL) fluid [38]. Accordingly, in a model of lung-injury induced by LPS, the BAL-fluid was found to contain increased MIF levels. Both local secretion of TNF and IL-8 and neutrophil accumulation could be decreased by immune-neutralizing MIF, indicating for MIF a role in the control of neutrophil infiltration into the lungs and in the promotion of the pulmonary inflammatory response in ARDS [58].

Given its pivotal role in the pathophysiology of infection and sepsis, targeting MIF may become an important strategy for immune-modulatory therapies in patients with sepsis and septic shock. In this context, an anti-MIF treatment has been demonstrated to offer protection in a murine model of lethal peritonitis even when administrated up to 8 hours after cecal ligation and puncture [7]. The fact that MIF levels are persistently increased over several days in septic patients may facilitate the therapeutic application of anti-MIF antibodies. This is a major advantage in comparison with previous unsuccessful strategies aiming at the neutralization of the rather fugacious cytokines TNF- $\alpha$ and IL-1 [4]. Of note, circulating levels of these cytokines rapidly decrease to baseline levels. It is therefore tempting to speculate that previous treatment strategies aiming at antagonizing these cytokines were probably initiated too late.

Interestingly, recent reports paradoxically suggest MIF to offer protection from noxious stimuli. In a mouse model of peritonitis, Pollak et al. observed an increased susceptibility for bacterial superinfection after MIF had been neutralized [59]. Likewise Calandra et al. reported the crucial function of MIF for bacterial killing in macrophages. MIF-deficient cells exhibited an impaired killing of gram-negative bacteria that could be rescued by an addition of recombinant MIF [60].

These intriguing findings suggest an ambiguous role for MIF that warrants further investigation in the context of distinct clinical settings.

\section{MIF INHIBITORS}

On the background of MIF's broad regulatory properties and crucial role in dysregulation of inflammatory diseases, various approaches have been undertaken to inhibit MIF activity. Although the molecular mechanisms underlying MIF's pleiotropic functions remain only partly understood, it is evident that MIF exerts at least part of its cytokine activity 
through signal transduction, initiated by direct binding to the CD74/CD44 extracellular receptor complex [18]. In addition, MIF is known to act as tautomerase, which is capable to isomerize substrates such as D-dopachrome and 44hydoxlphenyl pyruvate (HPP) [61-63]. The identification of the structure of MIF has prompted computer-assisted studies that aimed to find effective approaches to inhibit the MIF activity. Numerous small molecules were shown to inhibit tautomerase, including derivatives of dopachrome, acetaminophen (NAPQI), phenylpyruvic acid (cinnamates), Schiff bases, isoxazolines (ISO-1), and isothiocyanates (ITC) [25]. Although several inhibitors have been demonstrated to block the inflammatory response (e.g. the MIF-induced TNF secretion after stimulation with LPS) [8, 64], many of the suggested inhibitors appear to be not suitable for a pharmaceutical use. Major concerns involve lack of specificity, low potency, uncertainty about potential side effects in humans, and the only micromolar potency with respect to MIF inhibition [8]. The promising approaches demonstrating an increased survival after specific inhibition of MIF should encourage and stimulate further mechanistic studies to further identify potential MIF specific inhibitors.

\section{THE ROLE OF MIF AS A BIOMARKER IN SEPSIS AND INFLAMMATION}

As already mentioned above, MIF serum levels were found to be correlated with illness-severity and to be predictive for the clinical outcome in septic patients $[1,38$, 50-56]. Numerous research groups have tested the hypothesis that MIF levels could be used to distinguish noninfectious from infectious origins of inflammatory disease.
Lehmann et al. observed an increase of MIF levels in response to surgery. This increase did however not differ significantly in patients with infectious and non-infectious inflammation [65]. In contrast, de Mendonça-Filho et al. reported postoperative MIF release to be significantly more pronounced in cardiac surgical patients that in the postoperative period suffered from septic complications with microbiologically proven infection [66].

In another study, circulating MIF values were demonstrated to predict culture-proven bacteremia, with however only modest diagnostic power to distinguish bacterial from nonbacterial causes of sepsis in comparison to the wellestablished markers procalcitonin (PCT) and C-reactive protein (CRP). By combining different inflammatory markers, the predictive value was significantly enhanced [64]. In severely burned patients, Grieb et al. found the combination of MIF and PCT to have discriminate power for the differentiation of post-burn inflammation in survivors and lethal systemic inflammatory response syndrome (SIRS) or sepsis [67].

In conclusion, the diagnostic value of MIF is still controversial, most probably owing to the heterogeneity of the included patients in the different trials. Besides that, Sobierajski and colleagues demonstrated that preanalytical processing has a significant impact on the accuracy and validity of MIF analysis and demonstrated that MIF concentrations in directly processed blood samples were lower when compared to those samples that were processed later [68]. Furthermore, also the use of anticoagulants was shown to influence the circulating MIF levels in the blood.

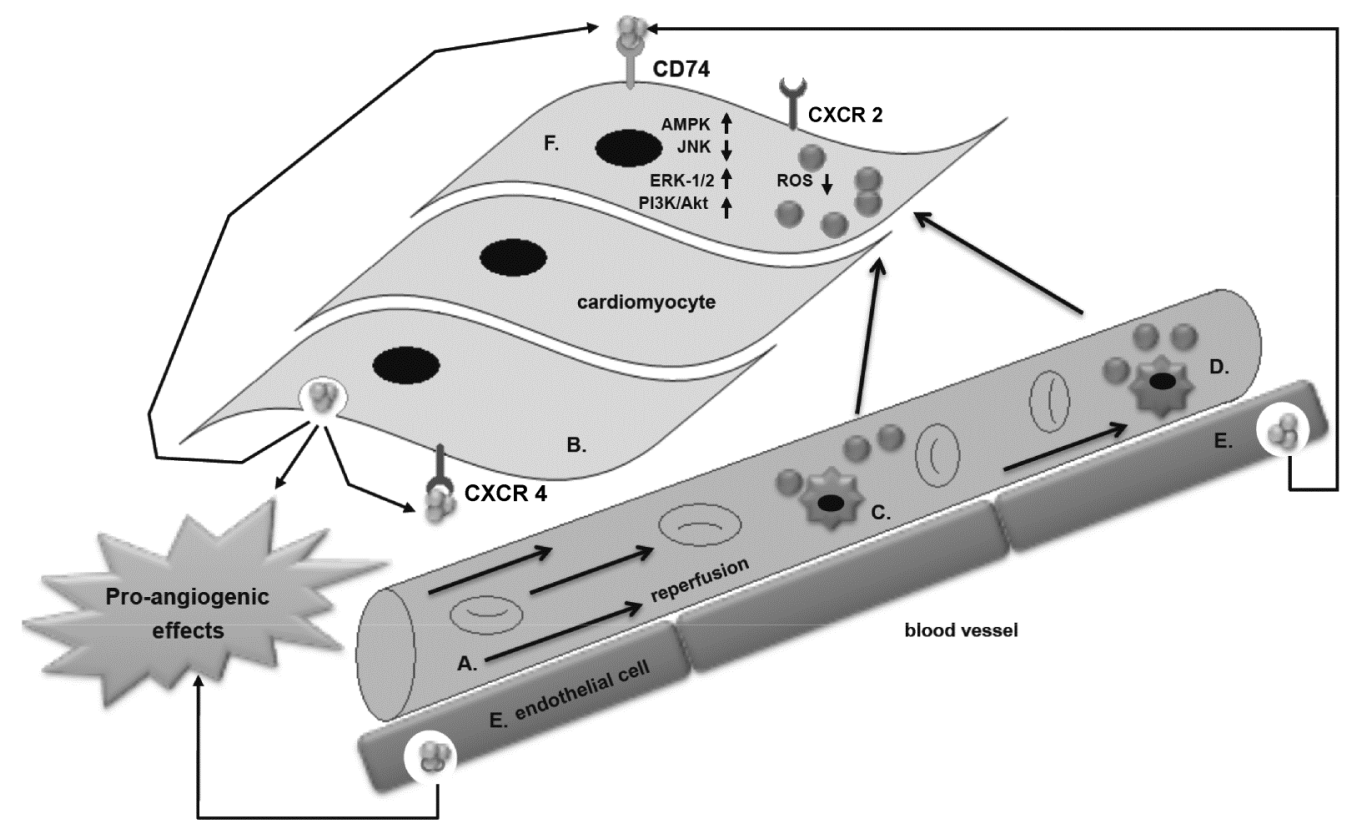

Fig. (2). The functional role of MIF during myocardial ischemia-reperfusion. Summary of the known MIF-mediated cardioprotective mechanisms. Myocardial ischemia with following reperfusion is known to (A) trigger an excessive release of MIF from cardiomyocytes (B) and endothelial cells $(\mathbf{E})$ and results in significant production of reactive oxygen species (pink circles) from xanthin oxidase, neutrophils (C) and other immune cells (D). The involved MIF-induced activation of cardioprotective kinases is summarized in F.

$\mathrm{AMPK}=$ adenosine monophosphate-activated protein kinase, $\mathrm{Akt}=$ protein $\mathrm{B}$ kinase; $\mathrm{ERK}=$ extracellular signal-regulated kinase; $\mathrm{PI} 3 \mathrm{~K}=$ phosphatidylinositol 3-kinase; ROS = reactive oxygen species; JNK = c-Jun N-terminal kinases. 
Moreover, some of the contradictory results might be attributable to the fact that MIF has ambiguous and partly opposing effects. Therefore larger and preferably multicenter studies are essential to elucidate if MIF may provide helpful information for risk stratification and prediction of organ dysfunction.

\section{THE ROLE OF MIF DURING MYOCARDIAL ISCHEMIA AND REPERFUSION}

Also in cardiovascular (patho-)physiology, the role of MIF is complex. Chagnon and colleagues found MIF to have pro-apoptotic effects in cardiomyocytes and to mediate cardiac dysfunction in sepsis and endotoxemia. Cardiomyocyte survival and myocardial function could be improved by inhibiting the pro-inflammatory effects of MIF [69]. Moreover, Gao et al. demonstrated in a murine model that the genetic deletion of MIF limits the myocardial damage and thus suggested MIF to exacerbate the ischemic tissue damage following ischemia and reperfusion [70].

In contrast, there is growing evidence that MIF regulates numerous pathways in myocardial ischemia/reperfusion injury (IRI) with an overall cardioprotective effect (Table 1, Fig. 2) intra- and extracellularly: First, the I/R triggered rapid MIF release from cardiomyocytes leads to an accumulation of extracellular MIF, which activates the adenosine monophosphate-activated protein kinase (AMPK) in an autocrine/paracrine manner [10]. The activation of AMPK stimulates anaerobic glycolysis in the ischemic myocardium, promotes the translocation of glucose transporter-4, and increases the uptake of glucose, hereby reducing myocardial damage and apoptosis. Second, MIF release from cardiomyocytes suppresses the JNK pathway [11]. JNK is critically involved in the regulation of essential cell survival processes including apoptosis, cell differentiation and inflammation and is known to boost myocardial damage in IRI. In comparison with MIF wildtype mice, hearts from MIF-knockout mice showed a significant increase in myocardial necrosis and apoptosis [11]. Third, MIF has been shown to stimulate neovascularization under hypoxic conditions [71], which is particularly interesting in patients suffering from myocardial ischemia or scheduled for cardiac surgery. Fourth, a selective site-specific S-nitros(yl)ation at Cys-81 results in an intrinsic thiolprotein oxidoreductase activity of intracellular MIF that counteracts oxidative stress caused by $I / R$ injury in myocardial infarction $[12,49,52,72]$. In cardiac surgery with cardiopulmonary bypass (CPB), the use of cardioplegic arrest induces myocardial IRI that mediates perioperative inflammation and the occurrence of postoperative organ dysfunction. Stoppe and colleagues have recently demonstrated in cardiac surgical patients that myocardial I/R triggers a rapid release of MIF [49, 73]. Elevated MIF levels after myocardial $\mathrm{I} / \mathrm{R}$ were associated with an enhanced antioxidant capacity that resulted in a less pronounced extend of organ dysfunctions [49] as indicated by an inverse correlation between the measured MIF levels and the

Table 1. Summary of MIF-induced cardioprotective effects during myocardial ischemia and reperfusion

\begin{tabular}{|c|c|c|c|}
\hline $\begin{array}{l}\text { Underlying pathophysiological } \\
\text { condition }\end{array}$ & Levels of MIF & Clinical significance and effects & References \\
\hline Acute myocardial infarction & $\begin{array}{l}\text { Significantly elevated MIF } \\
\text { levels in the serum }\end{array}$ & Unknown & {$[67]$} \\
\hline $\begin{array}{l}\text { Resuscitation after out of } \\
\text { hospital cardiac arrest }\end{array}$ & $\begin{array}{l}\text { Excessive increased MIF } \\
\text { serum levels after ROSC } \\
\text { with early decrease }\end{array}$ & Unknown & {$[66]$} \\
\hline Cardiac surgery & $\begin{array}{l}\text { Initial significant MIF } \\
\text { release with early decrease } \\
\text { after termination of surgery }\end{array}$ & $\begin{array}{l}\text { MIF levels immediately after termination of surgery: } \\
\text { - Positive correlation with cardiac power index } \\
\text { - Inverse correlation with organ dysfunction } \\
\text { - Reduced incidence of atrial fibrillation and acute kidney injury } \\
\text { Constantly elevated MIF levels in the later postoperative time } \\
\text { course: } \\
\text { - Associated with worse outcome and organ dysfunction }\end{array}$ & $\begin{array}{l}{[9,13} \\
60]\end{array}$ \\
\hline $\begin{array}{l}\text { Experimental data: } \\
\text { Ischemia/Reperfusion }\end{array}$ & $\begin{array}{l}\text { Hypoxia/Ischemia induced } \\
\text { increase of MIF secretion }\end{array}$ & $\begin{array}{l}\text { S-nitros(y)lation modification of MIF } \\
\text { Reduction of oxidative stress through MIF's own oxidoreductase activity } \\
\text { AMPK activation } \\
\text { Inhibition of JNK-mediated apoptosis } \\
\text { Neovascularisation and angiogenesis } \\
\text { ERK1/2- activation } \\
\text { Reduced infarct size, reduced apoptosis }\end{array}$ & $\begin{array}{l}{[72]} \\
{[12]} \\
{[10]} \\
{[11]} \\
{[65]} \\
{[38]} \\
{[12]}\end{array}$ \\
\hline
\end{tabular}

AMPK = adenosine monophosphate-activated protein kinase; Akt = protein B kinase; ERK = extracellular signal-regulated kinase; IL = interleukin; JNK = c-Jun N-terminal kinases; PI3K = phosphatidylinositol 3-kinase; ROS = reactive oxygen species; TNF = tumor necrosis factor. 
postoperatively assessed simplified acute physiology score (SAPS) II score. Furthermore patients with high MIF levels showed a significantly reduced incidence of atrial fibrillation (AF) and acute kidney injury (AKI) [49] and MIF values after reperfusion directly correlated with the cardiac power index and were inversely correlated with troponin $\mathrm{T}$ levels [9].

These findings, if confirmed and extended in larger cohort studies, may thus stimulate pharmacological approaches to modulate the intraoperative MIF secretion in cardiac surgery patients.

\section{CONCLUSION}

The pivotal role of MIF in the inflammatory response is well established. In contrast to initial assumptions, suggesting overall deleterious effects of this proinflammatory cytokine, emerging evidence indicates a protective role of MIF that might be of particular relevance in the setting of myocardial IRI.

Further experimental and clinical studies are warranted that will have to focus on the ambiguous characteristics of MIF in the context of distinct clinical settings.

\section{CONFLICT OF INTEREST}

The authors confirm that they have no conflicts of interests.

\section{ACKNOWLEDGEMENTS}

We are very thankful to numerous friends and colleagues with whom we have shared our research on MIF and who have helped us with valuable comments over many years.

\section{REFERENCES}

[1] Calandra, T.; Roger, T. Macrophage migration inhibitory factor: a regulator of innate immunity. Nat. Rev. Immunol., 2003, 3, 791800.

[2] Vincent, J. L.; Sakr, Y.; Sprung, C. L.; Ranieri, V. M.; Reinhart, K.; Gerlach, H.; Moreno, R.; Carlet, J.; Le Gall, J. R.; Payen, D. Sepsis in European intensive care units: results of the SOAP study. Crit. Care Med., 2006, 34, 344-353.

[3] Martin, G. S.; Mannino, D. M.; Eaton, S.; Moss, M. The epidemiology of sepsis in the United States from 1979 through 2000. N. Engl. J. Med., 2003, 348, 1546-1554.

[4] Opal, S. M.; Laterre, P. F.; Francois, B.; LaRosa, S. P.; Angus, D. C.; Mira, J. P.; Wittebole, X.; Dugernier, T.; Perrotin, D.; Tidswell, M.; Jauregui, L.; Krell, K.; Pachl, J.; Takahashi, T.; Peckelsen, C.; Cordasco, E.; Chang, C. S.; Oeyen, S.; Aikawa, N.; Maruyama, T.; Schein, R.; Kalil, A. C.; Van Nuffelen, M.; Lynn, M.; Rossignol, D. P.; Gogate, J.; Roberts, M. B.; Wheeler, J. L.; Vincent, J. L. Effect of eritoran, an antagonist of MD2-TLR4, on mortality in patients with severe sepsis: the ACCESS randomized trial. JAMA., 2013, 309, 1154-1162.

[5] Sprung, C. L.; Annane, D.; Keh, D.; Moreno, R.; Singer, M.; Freivogel, K.; Weiss, Y. G.; Benbenishty, J.; Kalenka, A.; Forst, H.; Laterre, P. F.; Reinhart, K.; Cuthbertson, B. H.; Payen, D.; Briegel, J. Hydrocortisone therapy for patients with septic shock. N. Engl. J. Med., 2008, 358, 111-124.

[6] Ranieri, V. M.; Thompson, B. T.; Barie, P. S.; Dhainaut, J. F.; Douglas, I. S.; Finfer, S.; Gardlund, B.; Marshall, J. C.; Rhodes, A.; Artigas, A.; Payen, D.; Tenhunen, J.; Al-Khalidi, H. R.; Thompson, V.; Janes, J.; Macias, W. L.; Vangerow, B.; Williams, M. D. Drotrecogin alfa (activated) in adults with septic shock. N. Engl. J. Med., 2012, 366, 2055-2064.

[7] Calandra, T.; Echtenacher, B.; Roy, D. L.; Pugin, J.; Metz, C. N.; Hultner, L.; Heumann, D.; Mannel, D.; Bucala, R.; Glauser, M. P.
Protection from septic shock by neutralization of macrophage migration inhibitory factor. Nat. Med., 2000, 6, 164-170.

[8] Al-Abed, Y.; Dabideen, D.; Aljabari, B.; Valster, A.; Messmer, D.; Ochani, M.; Tanovic, M.; Ochani, K.; Bacher, M.; Nicoletti, F.; Metz, C.; Pavlov, V. A.; Miller, E. J.; Tracey, K. J. ISO-1 binding to the tautomerase active site of MIF inhibits its pro-inflammatory activity and increases survival in severe sepsis. J. Biol. Chem., 2005, 280, 36541-36544.

[9] Stoppe, C.; Grieb, G.; Rossaint, R.; Simons, D.; Coburn, M.; Gotzenich, A.; Strussmann, T.; Pallua, N.; Bernhagen, J.; Rex, S. High postoperative blood levels of macrophage migration inhibitory factor are associated with less organ dysfunction in patients after cardiac surgery. Mol. Med., 2012, 18, 843-850.

[10] Miller, E. J.; Li, J.; Leng, L.; McDonald, C.; Atsumi, T.; Bucala, R.; Young, L. H. Macrophage migration inhibitory factor stimulates AMP-activated protein kinase in the ischaemic heart. Nature, 2008, 451, 578-582.

[11] Qi, D.; Hu, X.; Wu, X.; Merk, M.; Leng, L.; Bucala, R.; Young, L. H. Cardiac macrophage migration inhibitory factor inhibits JNK pathway activation and injury during ischemia/reperfusion. J. Clin. Invest., 2009, 119, 3807-3816.

[12] Koga, K.; Kenessey, A.; Powell, S. R.; Sison, C. P.; Miller, E. J.; Ojamaa, K. Macrophage migration inhibitory factor provides cardioprotection during ischemia/reperfusion by reducing oxidative stress. Antioxid. Redox Signa.l, 2011, 14, 1191-1202.

[13] Janeway, C. A., Jr.; Medzhitov, R. Innate immune recognition. Annu. Rev. Immunol., 2002, 20, 197-216.

[14] Calandra, T.; Bochud, P. Y.; Heumann, D. Cytokines in septic shock. Curr Clin Top Infect. Dis., 2002, 22, 1-23.

[15] David, J. R. Delayed hypersensitivity in vitro: its mediation by cellfree substances formed by lymphoid cell-antigen interaction. Proc Natl. Acad. Sci. US A, 1966, 56, 72-77.

[16] Bernhagen, J.; Calandra, T.; Mitchell, R. A.; Martin, S. B.; Tracey, K. J.; Voelter, W.; Manogue, K. R.; Cerami, A.; Bucala, R. MIF is a pituitary-derived cytokine that potentiates lethal endotoxaemia. Nature, 1993, 365, 756-759.

[17] Calandra, T.; Bernhagen, J.; Metz, C. N.; Spiegel, L. A.; Bacher, M.; Donnelly, T.; Cerami, A.; Bucala, R. MIF as a glucocorticoidinduced modulator of cytokine production. Nature, 1995, 377, 6871.

[18] Leng, L.; Metz, C. N.; Fang, Y.; Xu, J.; Donnelly, S.; Baugh, J.; Delohery, T.; Chen, Y.; Mitchell, R. A.; Bucala, R. MIF signal transduction initiated by binding to CD74. J. Exp. Med., 2003, 197, $1467-1476$

[19] Burger-Kentischer, A.; Goebel, H.; Seiler, R.; Fraedrich, G.; Schaefer, H. E.; Dimmeler, S.; Kleemann, R.; Bernhagen, J.; Ihling, C. Expression of macrophage migration inhibitory factor in different stages of human atherosclerosis. Circulation, 2002, 105, 1561-1566

[20] Bernhagen, J.; Krohn, R.; Lue, H.; Gregory, J. L.; Zernecke, A ; Koenen, R. R.; Dewor, M.; Georgiev, I.; Schober, A.; Leng, L.; Kooistra, T.; Fingerle-Rowson, G.; Ghezzi, P.; Kleemann, R.; McColl, S. R.; Bucala, R.; Hickey, M. J.; Weber, C. MIF is a noncognate ligand of CXC chemokine receptors in inflammatory and atherogenic cell recruitment. Nat. Med., 2007, 13, 587-596.

[21] Kanzler, I.; Liehn, E.A.; Koenen, R.R.; Weber, C. Anti-inflammatory therapeutic approaches to reduce acute atherosclerotic complications. Curr. Pharm. Biotechnol., 2012, 13, 37-45.

[22] Strieter, R. M.; Polverini, P. J.; Arenberg, D. A.; Walz, A Opdenakker, G.; Van Damme, J.; Kunkel, S. L. Role of C-X-C chemokines as regulators of angiogenesis in lung cancer. J. Leukoc. Biol., 1995, 57, 752-762.

[23] Mehrad, B.; Keane, M. P.; Strieter, R. M. Chemokines as mediators of angiogenesis. Thromb. Haemost., 2007, 97, 755-762.

[24] Strieter, R. M.; Polverini, P. J.; Kunkel, S. L.; Arenberg, D. A.; Burdick, M. D.; Kasper, J.; Dzuiba, J.; Van Damme, J.; Walz, A.; Marriott, D.; et al. The functional role of the ELR motif in CXC chemokine-mediated angiogenesis. J. Biol. Chem., 1995, 270, 27348-27357.

[25] Bai, F.; Asojo, O. A.; Cirillo, P.; Ciustea, M.; Ledizet, M.; Aristoff, P. A.; Leng, L.; Koski, R. A.; Powell, T. J.; Bucala, R.; Anthony, K. G. A novel allosteric inhibitor of macrophage migration inhibitory factor (MIF). J. Biol. Chem., 2012, 287, 30653-30663.

[26] Boisvert, W. A.; Santiago, R.; Curtiss, L. K.; Terkeltaub, R. A. A leukocyte homologue of the IL-8 receptor CXCR-2 mediates the 
accumulation of macrophages in atherosclerotic lesions of LDL receptor-deficient mice. J. Clin. Invest., 1998, 101, 353-363.

[27] Boisvert, W. A.; Rose, D. M.; Johnson, K. A.; Fuentes, M. E.; Lira, S. A.; Curtiss, L. K.; Terkeltaub, R. A. Up-regulated expression of the CXCR2 ligand $\mathrm{KC} / \mathrm{GRO}$-alpha in atherosclerotic lesions plays a central role in macrophage accumulation and lesion progression. Am. J. Pathol., 2006, 168, 1385-1395.

[28] Tillmann, S.; Bernhagen, J.; Noels, H. Arrest Functions of the MIF Ligand/Receptor Axes in Atherogenesis. Front. Immunol., 2013, 4, 115 .

[29] Burns, J. M.; Summers, B. C.; Wang, Y.; Melikian, A.; Berahovich, R.; Miao, Z.; Penfold, M. E.; Sunshine, M. J.; Littman, D. R.; Kuo, C. J.; Wei, K.; McMaster, B. E.; Wright, K.; Howard, M. C.; Schall, T. J. A novel chemokine receptor for SDF-1 and ITAC involved in cell survival, cell adhesion, and tumor development. J. Exp. Med., 2006, 203, 2201-2213.

[30] Mohle, R.; Bautz, F.; Rafii, S.; Moore, M. A.; Brugger, W.; Kanz, L. The chemokine receptor CXCR-4 is expressed on CD34+ hematopoietic progenitors and leukemic cells and mediates transendothelial migration induced by stromal cell-derived factor-1. Blood, 1998, 91, 4523-4530.

[31] Laudanna, C.; Alon, R. Right on the spot. Chemokine triggering of integrin-mediated arrest of rolling leukocytes. Thromb. Haemost., 2006, 95, 5-11.

[32] Lu, M.; Grove, E. A.; Miller, R. J. Abnormal development of the hippocampal dentate gyrus in mice lacking the CXCR4 chemokine receptor. Proc. Natl. Acad. Sci. U.S.A., 2002, 99, 7090-7095.

[33] Tarnowski, M.; Grymula, K.; Liu, R.; Tarnowska, J.; Drukala, J.; Ratajczak, J.; Mitchell, R. A.; Ratajczak, M. Z.; Kucia, M. Macrophage migration inhibitory factor is secreted by rhabdomyosarcoma cells, modulates tumor metastasis by binding to CXCR4 and CXCR7 receptors and inhibits recruitment of cancerassociated fibroblasts. Mol. Cancer Res., 2010, 8, 1328-1343.

[34] Degryse, B.; de Virgilio, M. The nuclear protein HMGB1, a new kind of chemokine? FEBS Lett., 2003, 553, 11-17.

[35] Oppenheim, J. J.; Biragyn, A.; Kwak, L. W.; Yang, D. Roles of antimicrobial peptides such as defensins in innate and adaptive immunity. Ann. Rheum. Dis., 2003, 62 Suppl 2, ii17-21.

[36] Wakasugi, K.; Schimmel, P. Two distinct cytokines released from a human aminoacyl-tRNA synthetase. Science, 1999, 284, 147-151.

[37] Calandra, T.; Bernhagen, J.; Mitchell, R. A.; Bucala, R. The macrophage is an important and previously unrecognized source of macrophage migration inhibitory factor. J. Exp. Med., 1994, 179, 1895-1902.

[38] Bozza, F. A.; Gomes, R. N.; Japiassu, A. M.; Soares, M.; CastroFaria-Neto, H. C.; Bozza, P. T.; Bozza, M. T. Macrophage migration inhibitory factor levels correlate with fatal outcome in sepsis. Shock, 2004, 22, 309-313.

[39] Donnelly, S. C.; Haslett, C.; Reid, P. T.; Grant, I. S.; Wallace, W. A.; Metz, C. N.; Bruce, L. J.; Bucala, R. Regulatory role for macrophage migration inhibitory factor in acute respiratory distress syndrome. Nat. Med., 1997, 3, 320-323.

[40] Onodera, S.; Kaneda, K.; Mizue, Y.; Koyama, Y.; Fujinaga, M.; Nishihira, J. Macrophage migration inhibitory factor up-regulates expression of matrix metalloproteinases in synovial fibroblasts of rheumatoid arthritis. J. Biol. Chem., 2000, 275, 444-450.

[41] Roger, T.; David, J.; Glauser, M. P.; Calandra, T. MIF regulates innate immune responses through modulation of Toll-like receptor 4. Nature, 2001, 414, 920-924.

[42] Mitchell, R. A.; Liao, H.; Chesney, J.; Fingerle-Rowson, G.; Baugh, J.; David, J.; Bucala, R. Macrophage migration inhibitory factor (MIF) sustains macrophage proinflammatory function by inhibiting p53: regulatory role in the innate immune response. Proc. Natl. Acad. Sci. U S A, 2002, 99, 345-350.

[43] Fingerle-Rowson, G.; Koch, P.; Bikoff, R.; Lin, X.; Metz, C. N.; Dhabhar, F.S.; Meinhardt, A.; Bucala, R. Regulation of macrophage migration inhibitory factor expression by glucocorticoids in vivo. Am. J. Pathol., 2003, 162, 47-56.

[44] Mitchell, R. A.; Metz, C. N.; Peng, T.; Bucala, R. Sustained mitogen-activated protein kinase (MAPK) and cytoplasmic phospholipase A2 activation by macrophage migration inhibitory factor (MIF). Regulatory role in cell proliferation and glucocorticoid action. J. Biol. Chem., 1999, 274, 18100-18106.

[45] Lue, H.; Dewor, M.; Leng, L.; Bucala, R.; Bernhagen, J. Activation of the JNK signalling pathway by macrophage migration inhibitory factor (MIF) and dependence on CXCR4 and CD74. Cell. Signal., 2011, 23, 135-144.

[46] Tsuge, T.; Menon, S.; Tong, Y.; Wei, N. CSN1 inhibits c-Jun phosphorylation and down-regulates ectopic expression of JNK1. Protein Cell, 2011, 2, 423-432.

[47] Kleemann, R.; Hausser, A.; Geiger, G.; Mischke, R.; BurgerKentischer, A.; Flieger, O.; Johannes, F. J.; Roger, T.; Calandra, T.; Kapurniotu, A.; Grell, M.; Finkelmeier, D.; Brunner, H.; Bernhagen, J. Intracellular action of the cytokine MIF to modulate AP-1 activity and the cell cycle through Jab1. Nature, 2000, 408, 211-216.

[48] Petrovsky, N.; Socha, L.; Silva, D.; Grossman, A. B.; Metz, C.; Bucala, R. Macrophage migration inhibitory factor exhibits a pronounced circadian rhythm relevant to its role as a glucocorticoid counter-regulator. Immunol. Cell. Biol., 2003, 81, 137-143.

[49] Stoppe, C.; Werker, T.; Rossaint, R.; Dollo, F.; Lue, H.; Wonisch, W.; Menon, A.; Goetzenich, A.; Bruells, C. S.; Coburn, M.; Kopp, R.; Bucala, R.; Bernhagen, J.; Rex, S. What is the significance of perioperative release of macrophage migration inhibitory factor in cardiac surgery? Antioxid. Redox Signal., 2013, 19, 231-239.

[50] Beishuizen, A.; Thijs, L. G.; Haanen, C.; Vermes, I. Macrophage migration inhibitory factor and hypothalamo-pituitary-adrenal function during critical illness. J. Clin. Endocrinol. Metab., 2001, 86, 2811-2816.

[51] Gando, S.; Sawamura, A.; Hayakawa, M.; Hoshino, H.; Kubota N.; Nishihira, J. High macrophage migration inhibitory factor levels in disseminated intravascular coagulation patients with systemic inflammation. Inflammation, 2007, 30, 118-124.

[52] Thiele, M.; Bernhagen, J. Link between macrophage migration inhibitory factor and cellular redox regulation. Antioxid. Redox Signal., 2005, 7, 1234-1248.

[53] Leaver, S. K.; MacCallum, N. S.; Pingle, V.; Hacking, M. B.; Quinlan, G. J.; Evans, T. W.; Burke-Gaffney, A. Increased plasma thioredoxin levels in patients with sepsis: positive association with macrophage migration inhibitory factor. Intensive Care Med., 2010, 36, 336-341.

[54] Sprong, T.; Pickkers, P.; Geurts-Moespot, A.; van der VenJongekrijg, J.; Neeleman, C.; Knaup, M.; Leroy, D.; Calandra, T.; van der Meer, J. W.; Sweep, F.; van Deuren, M. Macrophage migration inhibitory factor (MIF) in meningococcal septic shock and experimental human endotoxemia. Shock, 2007, 27, 482-487.

[55] Ostergaard, C.; Benfield, T. Macrophage migration inhibitory factor in cerebrospinal fluid from patients with central nervous system infection. Crit. Care, 2009, 13, R101.

[56] Renner, P.; Roger, T.; Bochud, P. Y.; Sprong, T.; Sweep, F. C.; Bochud, M.; Faust, S. N.; Haralambous, E.; Betts, H.; Chanson, A. L.; Reymond, M. K.; Mermel, E.; Erard, V.; van Deuren, M.; Read, R. C.; Levin, M.; Calandra, T. A functional microsatellite of the macrophage migration inhibitory factor gene associated with meningococcal disease. FASEB J., 2012, 26, 907-916.

[57] Otukesh, H.; Fereshtehnejad, S. M.; Hoseini, R.; Hekmat, S.; Chalian, H.; Chalian, M.; Bedayat, A.; Salman Yazdi, R.; Sabaghi, S.; Mahdavi, S. Urine macrophage migration inhibitory factor (MIF) in children with urinary tract infection: a possible predictor of acute pyelonephritis. Pediatr. Nephrol., 2009, 24, 105-111.

[58] Makita, H.; Nishimura, M.; Miyamoto, K.; Nakano, T.; Tanino, Y.; Hirokawa, J.; Nishihira, J.; Kawakami, Y. Effect of antimacrophage migration inhibitory factor antibody on lipopolysaccharide-induced pulmonary neutrophil accumulation. Am. J. Respir. Crit. Care. Med., 1998, 158, 573-579.

[59] Pollak, N.; Sterns, T.; Echtenacher, B.; Mannel, D. N. Improved resistance to bacterial superinfection in mice by treatment with macrophage migration inhibitory factor. Infect. Immun., 2005, 73, 6488-6492.

[60] Roger, T.; Delaloye, J.; Chanson, A. L.; Giddey, M.; Le Roy, D.; Calandra, T. Macrophage migration inhibitory factor deficiency is associated with impaired killing of gram-negative bacteria by macrophages and increased susceptibility to Klebsiella pneumoniae sepsis. J. Infect. Dis., 2013, 207, 331-339.

[61] Sun, H. W.; Bernhagen, J.; Bucala, R.; Lolis, E. Crystal structure at 2.6-A resolution of human macrophage migration inhibitory factor. Proc. Natl. Acad. Sci. U S A, 1996, 93, 5191-5196.

[62] Sun, H. W.; Swope, M.; Cinquina, C.; Bedarkar, S.; Bernhagen, J.; Bucala, R.; Lolis, E. The subunit structure of human macrophage 
migration inhibitory factor: evidence for a trimer. Protein Eng., 1996, 9, 631-635.

[63] Ouertatani-Sakouhi, H.; El-Turk, F.; Fauvet, B.; Roger, T.; Le Roy, D.; Karpinar, D. P.; Leng, L.; Bucala, R.; Zweckstetter, M.; Calandra, T.; Lashuel, H. A. A new class of isothiocyanate-based irreversible inhibitors of macrophage migration inhibitory factor. Biochemistry, 2009, 48, 9858-9870.

[64] Dabideen, D. R.; Cheng, K. F.; Aljabari, B.; Miller, E. J.; Pavlov, V. A.; Al-Abed, Y. Phenolic hydrazones are potent inhibitors of macrophage migration inhibitory factor proinflammatory activity and survival improving agents in sepsis. J. Med. Chem., 2007, 50, 1993-1997.

[65] Lehmann, L. E.; Novender, U.; Schroeder, S.; Pietsch, T.; von Spiegel, T.; Putensen, C.; Hoeft, A.; Stuber, F. Plasma levels of macrophage migration inhibitory factor are elevated in patients with severe sepsis. Intensive Care Med., 2001, 27, 1412-1415.

[66] de Mendonca-Filho, H. T.; Gomes, R. V.; de Almeida Campos, L. A.; Tura, B.; Nunes, E. M.; Gomes, R.; Bozza, F.; Bozza, P. T.; Castro-Faria-Neto, H. C. Circulating levels of macrophage migration inhibitory factor are associated with mild pulmonary dysfunction after cardiopulmonary bypass. Shock, 2004, 22, 533537.

[67] Grieb, G.; Simons, D.; Piatkowski, A.; Bernhagen, J.; Steffens, G.; Pallua, N. Macrophage migration inhibitory factor-A potential diagnostic tool in severe burn injuries? Burns, 2010, 36, 335-342.

[68] Sobierajski, J.; Hendgen-Cotta, U. B.; Luedike, P.; Stock, P.; Rammos, C.; Meyer, C.; Kraemer, S.; Stoppe, C.; Bernhagen, J.;
Kelm, M.; Rassaf, T. Assessment of macrophage migration inhibitory factor in humans: protocol for accurate and reproducible levels. Free Radic. Biol. Med., 2013, 63, 236-242.

[69] Chagnon, F.; Metz, C. N.; Bucala, R.; Lesur, O. Endotoxin-induced myocardial dysfunction: effects of macrophage migration inhibitory factor neutralization. Circ. Res., 2005, 96, 1095-1102.

[70] Gao, X. M.; Liu, Y.; White, D.; Su, Y.; Drew, B. G.; Bruce, C. R.; Kiriazis, H.; Xu, Q.; Jennings, N.; Bobik, A.; Febbraio, M. A.; Kingwell, B. A.; Bucala, R.; Fingerle-Rowson, G.; Dart, A. M.; Morand, E. F.; Du, X. J. Deletion of macrophage migration inhibitory factor protects the heart from severe ischemiareperfusion injury: a predominant role of anti-inflammation. $\mathrm{J}$. Mol. Cell. Cardiol., 2011, 50, 991-999.

[71] Amin, M. A.; Volpert, O. V.; Woods, J. M.; Kumar, P.; Harlow, L. A.; Koch, A. E. Migration inhibitory factor mediates angiogenesis via mitogen-activated protein kinase and phosphatidylinositol kinase. Circ. Res., 2003, 93, 321-329.

[72] Luedike, P.; Hendgen-Cotta, U. B.; Sobierajski, J.; Totzeck, M.; Reeh, M.; Dewor, M.; Lue, H.; Krisp, C.; Wolters, D.; Kelm, M.; Bernhagen, J.; Rassaf, T. Cardioprotection through Snitros(yl)ation of macrophage migration inhibitory factor. Circulation, 2012, 125, 1880-1889.

[73] Stoppe, C.; Fries, M.; Rossaint, R.; Grieb, G.; Coburn, M.; Simons, D.; Brucken, D.; Bernhagen, J.; Pallua, N.; Rex, S. Blood levels of macrophage migration inhibitory factor after successful resuscitation from cardiac arrest. PLoS One, 2012, 7, e33512. 